
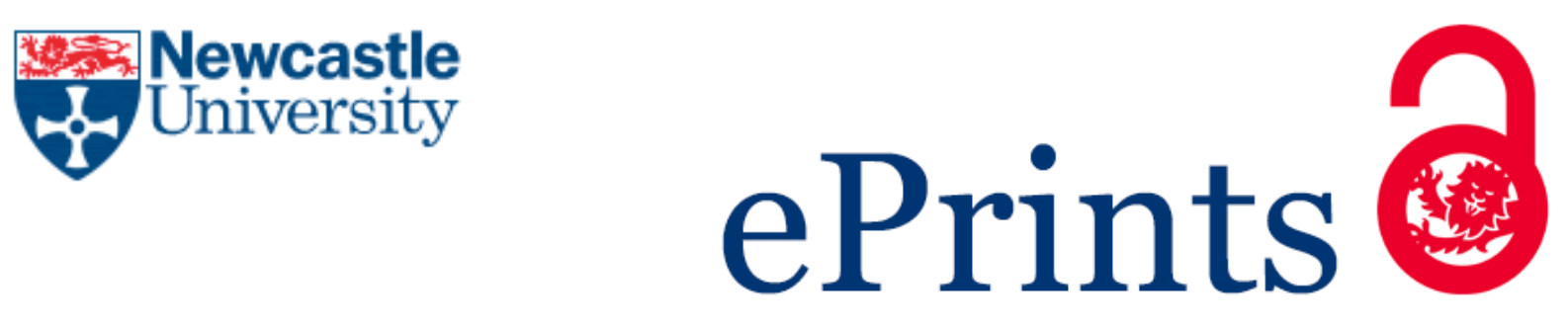

Osei-Frimpong $K$, Wilson A, Lemke F.

Patient co-creation activities in healthcare service delivery at the micro level:

the influence of online access to healthcare information.

Technological Forecasting and Social Change (2016)

DOI: http://dx.doi.org/10.1016/j.techfore.2016.04.009

Copyright:

(C) 2016. This manuscript version is made available under the CC-BY-NC-ND 4.0 license

DOI link to article:

http://dx.doi.org/10.1016/j.techfore.2016.04.009

Date deposited:

$19 / 04 / 2016$

Embargo release date:

15 October 2017

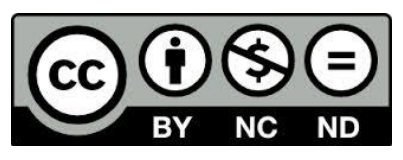

This work is licensed under a

Creative Commons Attribution-NonCommercial-NoDerivatives 4.0 International licence 


\title{
Patient co-creation activities in healthcare service delivery at the micro level: the influence of online access to healthcare information
}

\author{
Kofi Osei-Frimpong ${ }^{\mathrm{a}}$, AlanWilson ${ }^{\mathrm{b}}$, Fred Lemke $^{\mathrm{c}}$
}

\begin{abstract}
a. Business School, Ghana Institute of Management and Public Administration, Q6 P O Box AH 50, Achimota, Accra, Ghana

b. Department of Marketing, University of Strathclyde, Glasgow, United Kingdom

c. Newcastle University Business School, Services Marketing Research Group, 5

Barrack Road, Newcastle upon Tyne NE1 4SE, United Kingdom
\end{abstract}

\begin{abstract}
The healthcare sector has undergone a number of transformations in recent years, partly due to recent advances in technology. This triggered our study to examine patients' desire to seek health information largely driven by increased access via the Internet and the cumulative impacts on value co-creation. We employed a sequential exploratory design involving a phenomenological approach in the qualitative phase, followed by a quantitative survey design to further our understanding of the influence of technology in co-creating value in healthcare at the micro level. Advances in technology have empowered patients to be informed, which enabled them to play an active role in clinical encounters with the doctor. The findings suggest pre-encounter information search impacts positively on improved service engagement and commitment to compliance with medical instructions. It does this by shaping the nature of interactions; enhancing provider-patient orientation; and increasing their involvement in a shared decision-making process. From a theoretical perspective, our study integrates multiple research perspectives (e.g., access to information, online information seeking and knowledge creation, healthcare consultation models, etc.) and extends research on patient integration, participation, and co-creation of value. The conceptualization of value co-creation activities in this study suggests a need for service providers to adopt delivery approaches that would effectively integrate patient resources to co-create value.
\end{abstract}

\section{Keywords:}

Value Co-creation, Online Health Information, Service Encounter Process, Healthcare, Mixed Methods 


\subsection{INTRODUCTION}

Recently, patient participation in co-creating value has received much credence in healthcare research. Their active participation in clinical encounters is well documented to improve expected service outcomes (Bitner et al., 1997; Gill et al., 2011; McColl-Kennedy et al., 2012). Furthermore, the upsurge of consumerism in healthcare (Jaakkola and Halinen, 2006), whereby patients seek information from several sources, including the Internet or online communities, is changing the face of clinical encounters and provider relationships (Gutierrez et al., 2014; Heidenreich and Handrich, 2015; Nambisan and Nambisan, 2009; Silver, 2015). These advancements, coupled with improved cloud computing technology (an on-demand, self-service Internet infrastructure that enables the user to access computing resources on multiple devices in various locations), make cloud healthcare services a real option (Lai and Wang, 2015). As a result, clinical encounters in relation to healthcare consultation models have undergone a number of transformations, including the movement away from a paternalistic approach towards patients (i.e. one directed entirely by the doctor) to one that is more patient-centered (Laing et al., 2002; Taylor, 2009), all in the quest to satisfy the patient's needs as a consumer. Given that consumers of healthcare are also becoming more demanding with higher expectations, some doctors find this consumerist attitude unacceptable but tolerate this practice and improve on their delivery approach (Osei-Frimpong et al., 2015).

Considering these consumerist behaviours exhibited by patients, their active participation in clinical encounters is deemed critical in relation to managing their health or ill conditions (Gallan et al., 2013). As a result, sharing ideas or contributing to the decision-making process with healthcare providers is essential in order to enhance treatment options as well as improve on expected health outcomes (Elg et al., 2012; McColl-Kennedy et al., 2012; Osei-Frimpong et al., 2015). To co-create improved healthcare, patient's active participation is viewed as being important (Gallan et al., 2013; Hausman, 2004; Jaakkola and Halinen, 2006). However, not all patients are willing to engage in co-creation taking into account, the patient's ability and competence in co-creating value as well as their role clarity (McColl-Kennedy et al., 
2012), which also reflects in the challenges purported to ensue during clinical encounters (Hardyman et al., 2015; Jaakkola and Halinen, 2006).

Technological advancements have provided a platform for easy access to information for patients (Fiksdal et al., 2014; Peine and Moors, 2015; Zhao et al., 2015). This has, in a way, changed the nature of consultation models in healthcare, in which case, the patient is now considered active rather than being a passive subject (McColl-Kennedy et al., 2012). In effect, online resources (including the internet, patient community forums, etc.) play a vital role in the health of an individual and the healthcare system as a whole (Cotten and Gupta, 2004; Hajli, 2014). In the healthcare industry, the adoption of technology faces many challenges (e.g., lack of time, lack of financial resources, see, Saborowski and Kollak, 2015) and it is interesting to note that the technology lag in this unique industry has been identified long ago (cf. Kaufmann, 1973). This does not mean that technology is unimportant. In fact, the technology dimension has been widened to Health Information Technology (HIT). Its adoption remains particularly slow in this sector (Behkami and U. Daim, 2012), although reliable information and effective communication are critical elements in public health practices. Likewise, empowering patients through information dissemination tends to bridge the knowledge asymmetry gap to some extent, which is also likely to improve on the clinical engagement practices in the consulting room (Nambisan and Nambisan, 2009). Technology has the potential to be an experience-enriching and value-creating component in this one-toone setting.

In related studies on co-creating healthcare, some authors have focussed on patient value creating practice styles (McColl-Kennedy et al., 2012), micro level influencing factors of value co-creation from the focal dyad (doctor-patient) perspective (Osei-Frimpong et al., 2015), and models of co-creation taking into consideration the nature of leadership of the online health community and the nature of knowledge activity facilitated by the online health community (Ayers and Kronenfeld, 2007; Gutierrez et al., 2014; Nambisan and Nambisan, 2009; Woo et al., 2015). To our knowledge, there exist no empirical studies that examine the 
influence of online information seeking on patient co-creation activities in healthcare at the micro level (service-for-service exchange that occurs among individual actors) despite an increased e-health literacy rate. According to the most recent study on this issue, $59 \%$ of all adults in the United States looked for health information online in 2012 (Fox and Duggan, 2013). This study, therefore, fills this void by providing an empirical perspective of the influence of online health information search on patient co-creation activities in healthcare service delivery at the micro level. The study primarily sheds light on the influence of information seeking on the encounter process and how this cumulatively impacts on the expected service outcomes. The nested effects established in this study also differentiate it from previous research. From a theoretical perspective, our study integrates multiple research disciplines (e.g., access to information, online information seeking and knowledge creation, healthcare consultation models, etc.) and extends research on patient integration, participation, and co-creation of value.

The study employs a mixed method approach to provide deeper insight into the concept and presents a model that is quantitatively tested. The objectives of this paper are two-fold. Firstly, to understand patients' motivation in online health information search, and how this influences their engagement with the provider during consultation. Secondly, to develop a model of co-creation in healthcare and ascertain the cumulative effects of online resources on the expected outcomes.

\subsection{THEORETICAL FRAMEWORK}

\subsection{Resources as a vehicle for co-creation}

Value co-creation requires the collaborative activities of actors involved in the service exchange (Epp and Price, 2011; Frow and Payne, 2011), which are dependent on the capabilities and resources available to the provider (e.g., expertise, technology etc.) and the consumer (e.g., knowledge) as the two relevant parties (Peters et al., 2014). For the purposes of this study, McColl-Kennedy et al.'s (2012, p.375) definition of customer value co-creation 
is adopted: the "benefit realized from integration of resources through activities and interactions with collaborators in the customer's service network".

More recently, Lusch and Vargo (2014, p.15) placed emphasis on "four FPs [foundational premises] in particular that capture the essence of S-D logic [service-dominant logic]", considered as axioms. Axiom $3\left(\mathrm{FP}_{9}\right)$ states, "All economic and social actors are resource integrators" (ibid., p.74). Within S-D logic, resource integration refers to how actors "integrate and transform micro-specialised competences into complex services that are demanded in the marketplace" (Vargo and Lusch, 2008, p.7). This implies that service cannot be separated from the resource integrating activities performed by the involved actors taking into consideration their operant resources (e.g., knowledge and skills, see, Peters et al., 2014). McColl-Kennedy et al. (2012) placed emphasis on the fact that access to resources not only influence healthcare outcomes, but rather how these resources are adopted in relation to the resource integration process. Furthermore, Lusch and Vargo (2014, p.77) note that, "the effectual actor makes adjustments as the resource-integration and resource-creation process unfolds".

The importance of resource integration illustrates the dynamic nature of value co-creation, which is also evident in the different experiences and value (benefits) created for actors in a service exchange and determined by the beneficiary (Lemke et al., 2011; Lusch and Nambisan, 2015; Lusch and Vargo, 2014). Co-creation involves encounters that provide an enabling environment and motivation for actors to create value (Payne et al., 2009). These encounters tend to provide the means for engagement between the actors, which could be initiated by the provider, patient or both (Alam, 2013; Payne et al., 2008). Furthermore, value co-creation occurs when two service systems have congruent expectations in a way in which the available resources should be used in the course of their interactions (Plé and Cáceres, 2010). They further note the implications of resources on value co-creation in cases where there are variances between the systems with regard to expectations of appropriate behaviour. Considering its criticality, ineffective integration of resources by actors could adversely affect 
value co-creation resulting in potential value co-destruction (Echeverri and Skålén, 2011). As part of resource integration, patients in healthcare delivery seek to equip and enhance their knowledge on health related issues through pre-encounter information search, as briefly discussed in the following section.

\subsection{Online healthcare information seeking}

The application and different uses of information and communications technology (ICT) in healthcare has been reported extensively in the extant literature. Caridà et al. (2014) note the essential role ICT plays in healthcare systems and the potential impact it has on the actors' responsibilities in the service delivery. Recent adoption of online communities (Hajli, 2014; Nambisan and Nambisan, 2009), hospital websites providing information and serving as an interactive platform with patients (Ayers and Kronenfeld, 2007; Chou and Chou, 2002; Hajli et al., 2015) amongst others have contributed to empowering patients which also reflects in increased participation in healthcare delivery (Caridà et al., 2014; Cotten and Gupta, 2004; Eysenbach et al., 2004).

Patients increased participation in healthcare service delivery is considered critical of which, knowledge resulting from healthcare information seeking plays a cardinal role (Ayers and Kronenfeld, 2007; Fiksdal et al., 2014). Health-information seeking is defined as "verbal and nonverbal messages ascertained via everyday interaction, either purposeful or serendipitous, by members in a self-defined network, that serve not only to reduce uncertainty regarding health status, but also to construct a social and personal (cognitive) sense of health" (Tardy and Hale, 1998, p.338). This reflects in Payne et al. (2008) assertion that access to information, resources, individual knowledge and skills (competence), need assessment, and cognitive behaviours are some of the attributes to assist the patient to create value. Kellogg et al. (1997) assert that patients seek information for clarification purposes that enables them to satisfy their cognitive needs. Essentially, patients need information on healthcare to enhance their performance during clinical encounters as well as perform their tasks as value co- 
creators (Ayers and Kronenfeld, 2007; Chou and Chou, 2002; Yi and Gong, 2013).

Essentially, knowledge in the service exchange and the sharing of information between providers and patients is critical in value co-creation (Nambisan and Nambisan, 2009; Spohrer and Maglio, 2008). The extant literature suggests health information seeking as the purposive acquisition of information from selected sources that guide health-related decisionmaking (Oh et al., 2013), which could also influence patient behaviours in relation to healthcare (Gutierrez et al., 2014; Silver, 2015). Gutierrez et al. (2014) note that patients with limited health literacy may not be able to understand and make appropriate decisions about their health during their engagement with healthcare providers, which could also result in increased health costs, and poor health outcomes (Berkman et al., 2011). However, technological advancements have provided a platform for patients to access health related information relevant to managing their ill conditions as a result of access to the internet (Ayers and Kronenfeld, 2007; Hajli et al., 2015; Silver, 2015). Patients access to online health information is likely to impact positively on their related health outcomes (Jamal et al., 2015), which might have led to the upsurge of online health information searching behaviours on the part of patients (Fiksdal et al., 2014).

To buttress the points elaborated, Yi and Gong (2013, p.1280) highlight two principal reasons why patients seek information: Firstly they assert that, information seeking "reduces uncertainties" and enables patients "to understand and control their co-creation environments". Secondly, "it enables them to master their role as value co-creators and become integrated into the co-creation process". Hence, online information seeking is likely to impact on patients' interactions, their involvement in the decision-making process as well an understanding of the provider-patient orientation.

While online health information seeking has received much credence in research, most studies have focused on information seeking behaviours (e.g., Fiksdal et al., 2014; Silver, 2015). Others have examined the influence of health information seeking on specific disease 
conditions (Jamal et al., 2015), and health literacy among patients (Berkman et al., 2011; Gutierrez et al., 2014). Consequently, empirical research to ascertain how online health information seeking influences the consultation process, which in effect could impact on the expected health outcomes leading to co-creation of value is scarce.

\subsection{Co-creating healthcare at the micro level}

Patient participation in healthcare services has received critical attention over the past years. Their active involvement in consultations is paramount in enhancing medical management decisions and outcomes (Araz and Jehn, 2013; McColl-Kennedy et al., 2012; Nambisan and Nambisan, 2009; Osei-Frimpong et al., 2015). Accordingly, value is said to be co-created through the interaction of service systems (Spohrer and Maglio, 2008). As highlighted in section 2.1, co-creation requires the integration of resources from both the provider and the patient. This presents quite a complex and multidimensional process in a healthcare setting at the micro level considering the actors involved (Caridà et al., 2014; McColl-Kennedy et al., 2012). As indicated by Chandler and Vargo (2011), the micro level context consists of two actors and the service-for-service exchange between them. Hence, understanding their roles is essential as this may be paramount to improving healthcare outcomes.

Healthcare consultations are mostly face-to-face encounters, and therefore one actor's actions can affect the experiences of the other (Hardyman et al., 2015). More broadly, the service encounter is defined as "a period of time during which a consumer directly interacts with a service" (Bitner et al., 1990, p.72). This suggests that what transpires in the consulting room during the encounter process is critical in value co-creation. This multi-layered complexity emphasises the importance of understanding the cumulative influence of patients' online health information seeking on clinical encounters at the micro level. In clinical encounters, cocreation requires the active participation of both actors in the decision-making process (Godolphin, 2009), which depend on building a partnership in the encounter process, sharing detailed information, and allowing patients to deliberate and intimate their preferences and 
opinions during this process (Elwyn et al., 2010; Hausman, 2004). Consequently, this process could be enhanced by the increased literacy resulting from online healthcare information search (Ayers and Kronenfeld, 2007).

There is a need to understand the patients' inherent and social motivations to co-create value with the provider (Saarijarvi et al., 2013), which also requires the need for building partnerships between the actors (McColl-Kennedy et al., 2012; Taylor, 2009). Previous studies suggest that patient participation in consultations creates an active role in their behavioural intentions (Aveling and Martin, 2013; Ayers and Kronenfeld, 2007), which brings some level of responsibility on the part of the patient including their commitment to compliance (Chou and Chou, 2002; Dellande et al., 2004). Hence, enhancing patient's orientation and their involvement in the decision-making process during clinical encounters is critical, which could impact positively on their commitment to compliance (Hausman, 2004).

Patients' motivation in seeking online healthcare information in recent years has contributed to the transformations observed in healthcare service delivery, which must be encouraged (Gutierrez et al., 2014; Oh et al., 2013). This is likely to influence the co-creation activities of the patient in consultations at the micro level. In this vein, this study investigates patients' online information seeking, their motivation, and how this impacts on clinical encounters and the expected outcomes. Although pre-encounter online information seeking is considered essential in patient value co-creation activities, which in turn exert positive effects on patients' health outcomes, studies to operationalize the effects on clinical encounters and the expected outcomes are scarce. As a result, there are a number of questions yet to be answered. For instance, how does patients' increased access to online information influence the encounter process? What key elements of the encounter process are influenced? Does this indirectly affect the behavioural outcomes of the service (e.g., commitment to compliance)? This study aims to contribute in this regard by critically examining the provider-patient encounter process to operationalize the effects of increased access to online information on healthcare outcomes 
at the micro level. The following section discusses the methodology employed and the formulation of hypotheses for testing.

\subsection{METHODOLOGY}

To address the study objectives, we adopted a mixed methods approach, specifically a sequential exploratory design (SED) to explore the concept and test our proposed model. This method allows researchers to explore concepts qualitatively and build on it with quantitative research for generalization purposes (Harrison and Reilly, 2011). Furthermore, this method was adopted considering the exploratory nature of the concept and the limited results reported in the literature (Creswell and Plano Clark, 2011). The qualitative data was collected in the first phase of the research and analysed separately, which was further developed using quantitative research in the second phase of this study to investigate the formal relationships among the identified constructs (cf. Punjaisri and Wilson, 2011). The following sections provide an outline of the two data collection phases and a brief profile of the study context.

\subsection{The qualitative phase}

The qualitative research employed the phenomenological approach to understand the respondents' motivations of seeking information and how that influences the consultation process in the consulting room. In other words, how these available resources are integrated within the service encounter is important in driving the co-creation process. Phenomenological research is considered useful when exploring respondents' perceptions of a phenomenon or concept and how they make sense of it (Helkkula et al., 2012; Kvale and Brinkmann, 2009). In line with this approach, semi-structured depth interviews were conducted with 20 outpatients (patients who attend the hospital without staying there overnight) and 7 doctors who were purposively selected in two public hospitals in Ghana.

The interview questions aimed at exploring patients' use of online resources in seeking healthcare information and the motivations they have for searching for information prior to 
their visit to the hospital. Further probing questions were asked to provide a clear understanding of the consultation process and how their pre-encounter information search influenced such clinical encounters. In addition, doctors were interviewed to share their experiences on current patient participation behaviours in clinical encounters. This technique helped obtain rich insights into the respondents' experiences and perceptions in clinical encounters as they provided detailed contextual information that cannot be obtained from surveys (McColl-Kennedy et al., 2012). By employing a purposive sampling technique, respondents were interviewed after receiving ethical approval from the authors' academic institution and the health authorities in Ghana. Doctors were first recruited and interviewed, followed by interviewing three of the outpatients seen by each doctor. Outpatients were selected taking into consideration their educational background (mainly patients who could read and write), which may suggest that they are more likely to seek online health information. The respondent characteristics are presented in Table A.1.

\section{Insert Table A.1 here}

On average, each interview lasted about 50 minutes. Interviews were audio-recorded with the permission of the respondents and later transcribed and analysed. The researchers audited each transcript, checking it against the original recording for accuracy. The analysis of the data in this study was conducted following verbatim transcription of the interviews, and then thematic coding was utilised to reveal how information search influenced the consultation process and possible outcomes.

\subsubsection{The study context}

The provision of quality healthcare in Ghana has been the major concern of the Ministry of Health (MOH) and the Ghana Health Service (GHS) since the 1990s with various health sector reforms (Sika Avortri et al., 2011). Better education, reflected in the relatively high 
adult literacy rate in English (35.7\% in Ghana, see, GhanaStatisticalService, 2014), and increased access to the Internet and other related ICT applications has made the public more aware of and demand good quality healthcare service. Adult literacy rate in 'English only' is presented given that information on the Internet is mainly in English and not the Ghanaian local languages.

Public expenditure on health services averages 1.6\% of Gross Domestic Product (GDP) with a per capita government expenditure on health at $\$ 60$ in 2013 (WorldHealthOrganisation, 2015). With the goal of improving service delivery in the public healthcare sector, the GHS in achieving its medium-term strategic goals, invested in capacity building of various professionals, strengthening management systems, as well as putting in measures to launch an e-Health policy (GhanaHealthService, 2010). These measures include developing the use of information technology to improve information management and service delivery in collaboration with the National Information and Telecommunication Authority (NITA). Although this implementation is still at its infancy, patients engage in information seeking behaviours to keep them informed and enlightened on issues relating to healthcare.

\subsubsection{Analysis of qualitative study}

The abductive reasoning approach was followed in analysing the data (Dubois and Gadde, 2002) with the aim of understanding the respondents' motivations for seeking information and how the knowledge gained influenced the consultation process in the consulting room. Hence, thematic analysis of the data employed both an inductive and deductive manual approach (e.g., Gummerus and Pihlström, 2011). This allowed the researchers to thoroughly read the data, identify recurring themes independently, go back and forth between data and theory, and assign meanings to the themes. The sorting resulted in the following themes: preencounter information seeking, nature of interactions, shared decision-making (SDM), provider-patient orientation, commitment to compliance, and improved service engagement. These themes were categorised into three main stages of the clinical encounter: pre-encounter 
stage, encounter process, and expected outcomes. These are presented in section 3.1.3, which led to the development of our model.

In addressing reliability and validity of the results, the researchers independently coded the recurring themes identified through the interviews, which were then grouped into preliminary working categories (e.g., McColl-Kennedy et al., 2015). In addition, two independent researchers who are not part of the study were engaged to code the interviews into themes. They also independently grouped the themes into categories. Following Perreault and Leigh (1989), the index of reliability $\left(I_{\mathrm{r}}\right)$ obtained from the inter-judge categorisation was 0.85 , which is considered acceptable. This index of reliability takes into consideration the reliability of the whole coding process and not merely contrasting the level of agreement between judges (Osei-Frimpong et al., 2015).

\subsubsection{Qualitative research findings and discussion}

This section presents thematic areas derived from the qualitative interviews, which led to the development of our model in Figure A.1. Three key thematic areas are addressed to capture the process of co-creation at the micro level to include: pre-encounter online information search, the encounter process, and the post-encounter expected value outcomes (see Table A.2). These are briefly presented below:

\section{Insert Table A.2}

\section{Pre-encounter online information search}

This section explores the use of available resources and how these are well integrated within the service encounter. Knowledge asymmetry in a specialized field like the healthcare sector has created an information gap between practitioners and patients. However, in recent times, patients have developed the habit of searching for information, raising their awareness of 
health related issues, and in so doing, has become knowledgeable on some pertinent issues. This, in a way, has also empowered patients to be more actively engaged in consultations as presented in Table A.2. However, it is revealed that online pre-encounter information search can also result in 'knowledge conflict' between the actors, which leads to some negative experiences in the consulting room. To find out what motivates patients to seek information, the respondents were of the view that, reading health related issues equip them to be actively involved in clinical encounters with the doctor. Another motivational factor had to do with the fact that gaining knowledge in health related issues is stimulating and educational for managing their health in better ways, outside of the consulting room.

Both doctors and patients attest to the importance of information seeking on the part of the patient. Essentially, patients request information to clarify service requirements and satisfy other cognitive needs. Considering the upsurge of consumerism in healthcare, it is not surprising that patients desire to be more informed in order to enhance their level of engagement during consultations, although not without challenges as reported in Table A.2. The data revealed that, information seeking enables patients to improve on their interactions with the doctor as well as to understand the decision-making process. Clearly, patients are eager to be part of the process, which enhances their understanding of the provider-patient orientation as a consequence. These aspects are discussed below to elaborate on how these resources are integrated within the service encounter.

\section{The encounter process}

The encounter process reports what transpires in the consulting room between the doctor and the patient, which is influenced by the pre-encounter activities of both actors. We found three key elements of the encounter process (interactions, shared decision-making, and providerpatient orientation) that are driven by patients' increased access to online information. These are briefly presented below. 


\section{Interactions}

Interactions in the consultation is considered key as it drives the co-creation of the service between the patient and the doctor. This should be a two-way communication and not merely a question and answer (Q\&A) session. The changing nature of the interactive communication pattern is critical in value co-creation. Both doctors and patients admitted the importance of interactions in the consultation as presented in Table A.2. This presents opportunities for patients to share detailed information, seek clarification and enhance conclusions in relation to diagnosis. This encompassed an emphasis on listening, explaining, non-assertive response and a demonstration of understanding from both parties.

\section{Shared decision-making}

Shared decision-making process in healthcare service delivery is highly trumpeted as a healthcare delivery approach that is more likely to enhance clinical management decisions and expected outcomes, however, its application in practice has been erratic. The data revealed that patients who are informed are more inclined to have the tendency and desire to be involved in the decision-making process as presented in Table A.2. However, some doctors are not inclined to involve their patients in the decision-making process. These doctors were of the view that, patients trust their judgement, as they are regarded as experts and professionals whose interest is to provide the best care to the benefit of the patient (see Table A.2)

\section{Provider-patient orientation}

The research also revealed that patients who were informed had a better understanding of the provider-patient orientation, which is fundamental in the consultation process. From the research, both patients and doctors call for the need to understand and cooperate with each other to reduce the tendency of value conflict. However, patient's understanding of the provider's behaviours and orientation is essential to enhance care management and improve 
on service outcomes as presented in Table A.2. It is also evident that some doctors have embraced the practice to be more committed to the patient needs while others are yet to practice that. This approach could also improve patients' participation in consultations and especially in the case of patients who appear nervous and afraid to share information with the doctor. For such patients, this practice could help alleviate this problem and collaboratively improve on the outcome of the service perceived by both actors.

\section{Expected outcomes of the service}

Patients anticipate that their needs will be recognized in a way that makes them more than simply another transient patron. Hence, how patients are engaged in consultations largely affect their attitudes and perceptions toward the service, which impacts on the overall value realized. Expected service outcomes are explained as anticipated outcomes that could ensue resulting from the pre-encounter activities and encounter process outlined in this study.

The findings revealed enhanced service engagement as one of the expected outcome. In the context of this study, service engagement refers to how care is delivered and received between the doctor and the patient, taking into consideration the cognitive and relational factors that influence the patient's experience. Both doctors and patients admitted the importance of pre-encounter information search in shaping the engagement in the consulting room as presented in Table A.2. Similarly, both actors also attest to the fact that service encounters influence the patient's commitment to compliance. The actors attribute the effects of information search, as well as improved service engagement on commitment to compliance; however, some doctors maintained that patients' commitment to compliance is mainly behavioural (see Table A.2).

\subsection{Model development}

The qualitative study revealed the importance of resources in shaping the co-creation activities in healthcare service delivery at the micro level. The micro level context primarily 
examines the exchange process as it occurs among individual actors, which suggests that actors draw on their resources and competences to directly serve another actor (Chandler and Vargo, 2011). In this context, access to online resources equips patients to be knowledgeable, which also helps them engage better with doctors in the consulting room. Hence, in cocreation, integration of resources is critical as illustrated in our findings. As emphasized in S-D logic, the application of specialized knowledge and skills is essential for the benefit of another actor or the actor him/herself, which is largely fostered by technology (Lusch and Nambisan, 2015). This is evident in our findings, considering the patients' attempt to seek health related information to improve their understanding. The findings are in line with the literature and suggest that, patients' intention to seek for health information enhance their knowledge (Ayers and Kronenfeld, 2007; Nambisan and Nambisan, 2009), which partially bridges the knowledge asymmetry gap between doctors and patients. This enables patients to be actively involved in the encounter process with reference to interactions, shared decisionmaking, as well as enhancing the provider-patient orientation. The main themes or variables identified in this study, their meanings and propositions are presented in Table A.3, which led to the development of our conceptual model as shown in Figure A.1.

\section{Insert Table A.3 Here}

\section{Insert Figure A.1 Here}

From Table A.3, we conceptualise pre-encounter information seeking as activities patients engage in to purposively acquire online healthcare information to enhance their knowledge prior to the clinical encounters that guide health-related decision making (Oh et al., 2013; Tardy and Hale, 1998). This online information seeking behaviour instils confidence in patients' contributions leading to their active participation in the 
deliberations in the decision-making process as established in our findings. In effect, patients seem eager to interact with providers without reticence and are prepared to suggest options during the decision-making process. We explain interaction as a reciprocal action between two or more actors that require "mutual trust and collaborative relationships" (Alam, 2013, , p. 58). Whereas shared decision-making is explained as an approach where clinicians and patients share the best available evidence when faced with the task of making decisions, and where patients are supported to consider options, to achieve informed preferences (Elwyn et al., 2010).

The qualitative findings revealed that, pre-encounter information seeking on the part of the patients enables them to improve on their interactions with the doctor, participate in the decision-making process, as well as enhance their understanding of the provider-patient orientation. Kellogg et al. (1997) assert that patients seek information for clarification purposes that enables them to satisfy their cognitive needs. This also creates confidence in the patient to interact effectively with the doctor during the consultation. Also, preencounter information seeking could enhance a patient's understanding of the nature of the service, and their roles in co-creation (Kellogg et al., 1997; Yi and Gong, 2013).

The findings also indicate the emergence of knowledge conflict resulting from the increased knowledge on the part of the patient, which is reflected in their consumerist behaviours in the encounter. These can result in negative experiences in the consulting room on the part of both actors, which could lead to value co-destruction. In resolving knowledge conflict in consultations, it is essential for both actors to understand each other and embrace the changing trends notably in the case of the informed and enlightened patient. Knowledge should therefore be considered an essential resource in value cocreation in the context of healthcare as established in previous studies (e.g., Lusch and Vargo, 2014). Hence, there is a need to enhance the provider-patient orientation in clinical encounters. 
As a result, pre-encounter information seeking on the part of the patient is more likely to enhance their understanding of the provider-patient orientation in consultations. We conceptualise provider-patient orientation as the actor's capability to respond effectively to satisfy each party's expressed needs during service encounters. The findings suggest a need for actors to understand and cooperate with each other in order to reduce the tendency of knowledge conflict in service encounters. Bove and Johnson (2000) assert that a provider's commitment to understanding patient's behaviours and interest is critical in delivering service that is tailored to their needs, and hence instilling positive patient's emotions and perceptions of the service. Considering the different aspirations of the doctor and the patient, a better orientation is expected from both actors, which could bring changes in the practice approach, impacting on the service outcome. We, therefore, put forward the following hypotheses:

Patient pre-encounter online information search is likely to positively:

$H_{1 a}$ : improve the interactions between the doctor and patient in consultations

$H_{1 b}$ : impact on the patient's understanding of the provider-patient orientation in a healthcare setting

$H_{l c}$ : influence patients' involvement in the decision-making process in consultations

It is established from the findings that, pre-encounter information seeking on the part of the patient tends to influence the encounter process during consultations. Notably, patients are confident in their contribution and therefore actively participate in the consultation from start to finish. In essence, patients are eager to interact with the doctor, play an active role in the shared decision-making process, and tend to better understand the provider-patient orientation. However, doctors need to reorient to understand the consumerist behaviours of the patient as explained above. For instance, patients consider their participation in the decision-making process as being a critical aspect of the service encounter, which also gives them a sense of responsibility in managing their illness. These elements of the encounter process as presented in our findings, play a critical role in the value co-creation 
process. In support of previous studies (e.g., McColl-Kennedy et al., 2012), engaging the actors in value co-creating activities is likely to improve on the service delivery and the expected outcomes of the service encounter to the patient and the provider. As outlined above, the process of value co-creation brings to the fore a client oriented service approach in which case both actors are clearly understood and play their respective roles.

The findings suggest that pre-encounter information seeking greatly influences the service encounter process leading to the determination of expected outcomes. For the purposes of this study, expected outcomes are explained as anticipated outcomes that could ensue resulting from the pre-encounter activities and encounter process. This suggests that, the key elements of the encounter process highlighted in the findings (i.e., interaction, shared decision-making, and provider-patient orientation) are influenced by pre-encounter information seeking. In turn, these are likely to impact on the expected outcomes. The qualitative study found improved service engagement and increased commitment to compliance to medical instructions as the expected outcomes. We found that these expected outcomes to be influenced by enhancing the service encounter process. The literature suggest that misunderstandings in prescription decisions are attributed to the lack of patient participation in the decision-making process, which adversely affects the level of compliance (Britten et al., 2000). Hence, involving patients in service encounters is critical, which could impact positively on their commitment to compliance (Hausman, 2004). Consequently, active patient participation and interactions in consultations also play an active role in their behavioural intentions (Hsieh et al., 2004; Lunde, 1993), which also craves a sense of responsibility on the part of the patient including their commitment to compliance (Dellande et al., 2004). On this premise, we formulate the following hypotheses:

Enhancing the nature of interactions in clinical encounters is likely to positively;

$H_{2 a}$ : affect the level of service engagement between the doctor and patient within the healthcare setting 
$H_{2 b}$ : influence patients' commitment to compliance

Enhanced provider-patient orientation in consultations is likely to positively;

$H_{3 a}:$ affect the level of service engagement between the doctor and patient within the healthcare setting

$H_{3 b}$ : influence patients' commitment to compliance

Shared decision-making in consultations is likely to positively;

$H_{4 a}:$ affect the level of service engagement between the doctor and patient within the healthcare setting

$H_{4 b}:$ influence patients' commitment to compliance

In a similar vein, improving the service engagement takes into perspective the actors' approach in the service delivery process. The findings revealed that a positive approach to the engagement in the consulting room motivates patients to be more committed to comply with the doctor's instruction. The literature suggests that the approach and characteristics of the actors in the service encounter is more likely to impact on the outcomes of the service (e.g., Dellande et al., 2004; Echeverri and Skålén, 2011). As a result, improving the service engagement in consultations is likely to influence patient's commitment to compliance to medical instructions. We put forward this hypothesis:

$H_{5}$ : Improvement in the service engagement between the doctor and patient during the consultation process is likely to positively influence the patient's commitment to compliance to medical instructions

The qualitative study provided insights into the effects of pre-encounter information seeking on the part of the patient and how this influences the encounter process at the micro level. Specifically, the study provided insights into the key elements of the provider-patient encounter process that are directly influenced as a result of the patients' increased access to information, which also influences the expected outcomes. Drawing from the findings and the above hypotheses, we develop a measurement model as presented in Figure A.2 for empirical testing.

Insert Figure A.2 Here 


\subsection{Development of measurement instrument}

In line with Punjaisri and Wilson's (2011) approach, scale items were mainly drawn from existing scales in related literature on concepts parallel to the variables in the proposed model. These items were added on or modified with caution not to change their meanings with insights from the qualitative study (Appendix 1). As a result, all variables were measured using a five-point Likert-scale anchored with 1 (Strongly disagree), 3 (Uncertain), and 5 (Strongly agree).

\subsubsection{Quantitative phase - data collection}

By employing a systematic random technique, a survey involving 360 outpatients from 20 randomly selected public health facilities in the Accra and Tema metropolitan areas in Ghana were interviewed using a structured questionnaire. The research instrument was pre-tested by interviewing 20 outpatients from selected hospitals included in the main study. The clarity and understanding of the questionnaires ensured the reliability and content validity of the scale items in this particular research context (Chen and Quester, 2006). All scales items measured a Cronbach alpha $\alpha>0.7$ with correlation significance at the level of $p<0.05$ in the pre-test, indicating the robustness of the scales (Bagozzi and Yi, 2012). Scale items that measured a corrected item-total correlation of $<0.3$ were not included in the final version of the questionnaire (Chen and Quester, 2006).

The main study involved face-to-face interviews of 360 respondents using a structured questionnaire. Patients included in the study were those who had seen a doctor prior to the interviews. Outpatients were chosen because of the one to one encounter with the doctor in clinical consultations as compared to inpatients where a group of health professionals may be involved in the service encounter. A valid response rate of $86 \%$ was calculated, which suggest that issues of non-response bias was well controlled (cf. de Winter et al., 2005). The respondent characteristics are provided in Table A.4 below. 


\section{Insert Table A.4 here}

\subsubsection{Analysis and results}

All scales recorded Cronbach alpha of $\alpha>0.7$ with correlation significance at the level of $p<0.05$. An exploratory factor analysis (EFA) was conducted employing the principal component analysis technique (Hair et al., 2006) and Varimax rotation using SPSS 21.0. Following Kaiser (1970), the Kaiser-Meyer-Olin (KMO) measure of sampling adequacy was 0.84 above the threshold of 0.6 with $\rho$-values $<0.001$ for Barlett's test of Sphericity. This helped to fine-tune the measures to be included in the confirmatory factor analysis (CFA) after deleting some items that did not load well. Using AMOS 21.0 maximum likelihood estimation, CFA was performed using the extracted items from the EFA. The factor loadings (Appendix 1) and fit indices indicate a reasonably fit model $\left(\mathrm{CFI}=.972 ; \mathrm{GFI}=.925 ; \mathrm{RMSEA}=.041 ; \chi^{2}(230)\right.$ $\left.=366.316, \rho=0.06, \chi^{2} / d f=1.593\right)$. We also checked for multicollinearity using variance inflation factors (VIF) of all variables (Hartline et al., 2000). The findings suggest no evidence of high multicollinearity in the data following the recommended cut-off point of 10.00 .

\subsubsection{Validity and construct reliability}

Following the CFA, discriminant and convergent validity was assessed. Analysis of Fornell and Larcker's (1981) criterion, which compares the average variance extracted (AVE) for each variable or construct to the shared variance between constructs was performed. All constructs AVE exceeded .50 with composite reliabilities above .70 supporting convergent validity as presented in Table A.5. The AVE values of the constructs are greater than the square of the correlations, hence satisfying discriminant validity (Hair et al., 2006; Kim, 2000). The results suggest measures possess adequate construct validity, hence their acceptability for hypothesis testing (Mathieu and Taylor, 2006). 


\section{Insert Table A.5 here}

\subsubsection{Structural model measurement and model comparison}

Following the full structural model evaluation using AMOS 21.0, the results suggest an acceptable model fit to the data. The model evaluation presented the following fit indices $\left(\chi^{2}=\right.$ 399.488, $\mathrm{df}=232, \rho=.165, \mathrm{GFI}=.918, \mathrm{CFI}=.966, \mathrm{RMSEA}=.045)$. A detailed list of the standardized path coefficients (focal and alternative models) with their respective t-values is presented in Table A.6.

\section{Insert Table A.6 here}

After the model specification, the focal model was later compared with two rival models (alternative models 1 and 2), which is considered as one of the essential criteria of assessing its success and robustness (Bagozzi and Yi (1988). Anderson and Gerbing (1988) emphasise the appropriateness of model trimming in exploratory research of this nature, when it is not used as a substitute for a priori hypothesis development. Following Hartline et al.'s (2000) approach, the non-significant path was dropped to create a more parsimonious model. Hence, as a nested model, some of the parameters were constrained from a theoretical viewpoint to develop alternative models by removing one or more parameters from the focal model (Anderson and Gerbing, 1988).

Goodness-of-fit indices were obtained for all three models and compared to select the superior model. While some authors suggest the Chi square test (Hoyle, 1995) others have used the RMSEA, CFI and the Akaike Information Criterion (AIC) (Arnett et al., 2003; Lin and Hsieh, 2011). The AIC is generally used to compare rival models estimated (Kline, 2011), and smaller values of the AIC indicate a better fit of the model (Hu and Bentler, 1999). The rival models 
were compared using the Chi square test and the AIC, supported by the other goodness-of-fit statistics. The summary of fit statistics of all three models (thus, focal and alternative models) is presented in Table A.6 above.

The chi-square difference statistics between the focal model and the alternative models ( 1 and 2) were all significant at $\rho<0.001$, which suggests that, the models are different. Also the AIC value of the focal model was smaller compared to the other rival models and also reported better-fit indices. Although the differences among the alternative models are quite moderated, a comparison of the fit statistics from the three models indicates that the focal model is more parsimonious and fits somewhat better than the alternative models (Hartline et al., 2000).

\subsection{Discussion of results}

In relation to the model estimation/evaluation, the results suggest a positive influence of preencounter online information search on improving the level of service engagement in the consulting room. This is consistent with previous research (Chou and Chou, 2002; Kellogg et al., 1997; Nambisan and Nambisan, 2009; Yi and Gong, 2013), hence supporting hypotheses $\mathbf{H}_{\mathbf{1 a}}, \mathbf{H}_{\mathbf{1 b}}$ and $\mathbf{H}_{1 \mathbf{c}}$. The quantitative result also supports the qualitative findings, which explains patient motivation in pre-encounter information seeking that enhances their knowledge in relation to understanding some basic underlying issues with regard to their health condition.

Specifically, patient pre-encounter information seeking enabled by advances in technology significantly influence patients understanding of the provider-patient orientation, empowers patients to be more involved in the decision-making process, as well as enhancing the nature of interactions that ensue in the consulting room as reported in the qualitative findings. However, the strength of association of the relationships is reasonable as seen in the relatively low $\mathbf{R}^{\mathbf{2}}$ values as presented in Table A.6. These factors influenced by pre-encounter information search also positively improve the service engagement in consultations, hence, supporting hypotheses $\mathbf{H}_{2 \mathbf{a}}, \mathbf{H}_{3 \mathbf{a}}$ and $\mathbf{H}_{4 \mathbf{a}}$. This suggests that, motivating patients to have a keen 
interest in reading on health related issues would improve the care delivery approach in consultations. The findings corroborate previous studies (e.g., Chou and Chou, 2002; Cotten and Gupta, 2004; Jamal et al., 2015; Oh et al., 2013) and add more rigour by establishing the relationship between these variables.

Also, interactions (two-way communication rather than Q\&A sessions) and shared decisionmaking were found to positively influence patients' commitment to compliance. This meant that, once patients are actively involved in all facets of the clinical encounter, they develop a sense of responsibility in managing their condition, which is particularly important in value co-creation (Caridà et al., 2014; Osei-Frimpong et al., 2015). Even though the qualitative study suggested that many patients still do not get the opportunity to interact in consultations, they attested to the influence of such interaction on the expected health outcomes.

On the other hand, provider-patient orientation does not have any significant effect on patient's commitment to compliance, hence, hypothesis $\mathbf{H}_{\mathbf{4 b}}$ was not supported. This could be a result of the fact that, patients' consider other factors than just the provider orientation in the consulting room when it comes to compliance. The qualitative findings also shed light on this dimension as doctors argue patients' compliance to medical instructions as mainly behavioural. This is also re-echoed in previous studies that suggest that, patient compliance is largely influenced by their own attitudes and behaviours (e.g., Dellande et al., 2004; OseiFrimpong et al., 2015). Hence, an understanding of the provider-patient orientation might not necessarily influence their commitment to compliance with medical instructions.

The result also purports a positive relationship between improved service engagement and commitment to compliance with medical instructions; hence, hypothesis $\mathbf{H}_{5}$ is supported. This is in agreement with the qualitative findings suggesting that a positive approach to engagement in consultations motivates patients and instils some level of responsibility in relation to managing their condition and strictly adhering to the doctor's instructions. This result also supports claims of possible patient behavioural change in relation to the influence 
of pre-encounter online information seeking on health outcomes (Jamal et al., 2015). In effect, the results shed light on patients' co-creation activities at the micro level that ensues resulting from their increased access to online information. It is argued that, these activities improve patients' commitment to comply with medical instructions, which is considered critical in the value co-creation process. This post-encounter patient participatory behaviour (compliance) could be inferred as value-in-use (Auh et al., 2007), which has a high probability of leading to value creation at the micro level.

\subsection{THEORETICAL IMPLICATIONS}

This study empirically examined the micro level clinical encounter process between the doctor and patient leading to value co-creation as influenced by the availability of information aided by advancements in technology. How this cumulatively impacts on clinical encounters and potential outcomes was also examined. In value co-creation, it is envisaged that both actors (doctor and patient) engage in a way that effectively integrates resources (Lusch and Vargo, 2014; Peters et al., 2014), without which value cannot be created. The study provides an empirical understanding of how patients are keen to obtain online health information, which is brought to bear in consultations and in the effective integration with the doctor. In this respect, we present a model of value co-creation (Figure A.1) in a healthcare setting at the micro level, which is largely driven by access to online healthcare information on the part of the patient.

S-D logic considers the customer as "always a co-creator of value" (Lusch and Vargo, 2014, , p. 68). This consideration also presents a pluralistic view of value co-creation in relation to the changing relationship between providers and patients (customers) as well as a changing perspective on the role that patients play in service delivery. In this vein, understanding the influence of technology and patients' interest in seeking online health information, their motivations, and the effects this practice has on the doctor-patient encounter in the consulting room is essential. Having said that, patients' knowledge acquisition is purported to create negative experiences for both actors in the consulting room which has the potential to create 
value co-destruction (Osei-Frimpong et al., 2015). However, this study purports a significant positive impact on clinical engagement as well as a patient's commitment to compliance with medical instructions despite some negative experiences reported in consultations. Hence, patients' interest in seeking health information largely driven by increased access via the internet impacts positively on value co-creation as reported in this study.

Although this is considered an exploratory study, the use of a mixed methods approach involving both a qualitative and a quantitative phase sheds more light on the validity of the model developed and its potential utility in both theory and practice. The phenomenological approach enabled us to better understand patients' online healthcare information seeking and how this is utilised in consultations to add value to the care delivered and received. This also provided insight into the influence of online health information search on the encounter process, examining pertinent variables of interest, which have not been empirically examined in previous research. This led to the development of a model whose validation was supported by the results of the quantitative survey, highlighting the various important elements in the consultation process. These include interactions, shared decision-making, and provider-patient orientation. These important elements of the consultation if underplayed could be inimical to the overall service outcome. Hence, integrating the results of the two studies as per our research process adds rigour to our findings.

Our findings add to previous studies that have considered the individual importance of service elements including online healthcare information seeking (Ayers and Kronenfeld, 2007; Caridà et al., 2014), effective interactions in consultations (Hausman, 2004; Lin and Hsieh, 2011), shared decision-making (Elwyn et al., 2010; Godolphin, 2009), and provider-patient orientation (Daniel and Darby, 1997; Gill et al., 2011). We provide a holistic perspective by taking into account the nested effects of these elements in consultations, ensuring there is an active participation from start to finish in clinical encounters and the potential impact this practice has on expected service outcomes. From a theoretical perspective, our model integrates multiple research disciplines (e.g., access to information, online information seeking 
and knowledge creation, healthcare consultation models) and extends research on patient integration, participation, and co-creation of value. This also responds to calls for research to further our understanding on patient roles in value co-creation as part of service design and delivery (Ostrom et al., 2015).

Our conceptualization and findings suggest that the dependence of technology in promoting healthcare transformations and the participation of patients in consultations is unparalleled. Access to information and knowledge acquisition empowers patients to actively participate in clinical encounters, understand the service orientation, and suggest options in relation to the treatment plan. This suggests that the patients' role in value co-creation is essential leading to possible improved outcomes. It is therefore, incumbent on the actors to play their respective roles in service encounters to ensure effective integration of resources. This brings to the fore the importance of understanding the emerging roles of today's patient, and how this could influence the service outcome. Our findings, thus, contribute to the value co-creation literature and further provide an understanding of the influence of technological advancements on healthcare delivery at the micro level.

\subsection{MANAGERIAL IMPLICATIONS}

The study empirically revealed the importance of technology on patients' participation in clinical encounters impacting on expected service outcomes by examining the doctor-patient encounter level in the healthcare setting. The findings suggest that patients are motivated to search for health related information, which is aided by technological advancements. This may mean that, the patients' role in consultations has changed, as a result of them being better informed. As patients take up active roles in clinical encounters, there is a need for doctors to understand this transformation and orient themselves to the current behaviours and expectations.

The model provides insights into the service encounter processes between the healthcare provider and the patient. There is, therefore, a need for providers to adopt approaches that 
allow for better engagement with patients. Patients are actively involved in seeking online healthcare information aided by technology, which changes the complexion of the clinical encounters. Although it is seemingly impossible to completely bridge the knowledge asymmetry gap between the provider and the patient in such a knowledge intensive service, it is recommended that doctors encourage more interactions from patients and engage them in the decision-making process. Hence, a need to promote and practice a patient-centred approach in delivering care with patients being considered as partners in order to improve service outcomes.

Our conceptualisation of value co-creation underscores the influence of technology in driving the service encounter leading to potential service outcomes. Pre-encounter online healthcare information seeking on the part of patients enlightens and informs them, which provides avenues to explore in clinical encounters. As a result, patients are encouraged to interact effectively in consultations, understand the provider-patient orientation, and be involved in the decision-making process, which tends to improve their commitment to compliance with medical instructions. The findings revealed that, the ability of the parties involved in cocreation to communicate effectively ensures an understanding of each actor, which is imperative. This encompasses an emphasis on listening, explaining, using a non-assertive response and a demonstration of understanding.

Furthermore, the service encounter requires optimal cooperation from the doctor and the patient (McColl-Kennedy et al., 2012). The findings reveal the importance of the providerpatient orientation in the encounter leading to improved service engagement that influences value co-creation. This allows the actors to understand each other and the current trends in patient attitudes and behaviours in the consulting room. Hence, there is a need for doctors to vary their approach to the consultation and incorporate patient's views and expectations into the decisions that are taken. This also calls for better provider-patient orientation especially on the part of the doctors to deliver superior value to the patient. Furthermore, providers should not lose sight of the importance of a shared decision-making process, as this instils a 
sense of responsibility on the part of the patient in managing their ill condition. This practice empirically improves service engagement in consultations as well as patients' commitment to compliance, which is critical in value co-creation.

In light of the above, there is a need for service providers and doctors to understand the patient and not just limit the patient's role to the provision of information in relation to reporting symptoms. The study suggests a need for providers to take a holistic view of service delivery and consider the essential elements or areas in clinical encounters to empower patients to assume an active participatory role.

\subsection{CONCLUSION}

The empirical examination of what transpires in the consultation room between the doctor and patient revealed the importance of patient pre-encounter information seeking before clinical encounters. Patients are motivated to take advantage of the access to information aided by technological advancements to enhance their performance in co-creating value with the provider and for themselves. We contend that, pre-encounter online healthcare information seeking improves the service engagement and patients' commitment to compliance with medical instructions. However, this can only be achieved through the collaborative efforts of both parties (doctors and patients). This suggests a need for providers (doctors) to understand and accept the consumerist behaviours exhibited by these enlightened patients and adopt a holistic approach to care delivery. Hence, the integration of resources (knowledge and skills) plays a critical role in the co-creation of value.

The findings of this study provide robust support for the theoretical model and predicted relationships. However, like any research, this study was not without limitations. This study examined one aspect of patients' value co-creating activities, thus, information seeking via websites and other online communities to enlighten and inform them on health related issues and how this is utilised to improve on service engagement in clinical encounters and expected outcomes. As this may vary depending on the nature of the medical condition and the context 
of the consultation, it is important to note that further research is needed to expand on our study looking at co-creation in healthcare at the micro level.

Our study focused on what transpires in the consulting room and therefore, did not examine the post-encounter outcomes. As a result, our findings are only based on patients' commitment to compliance to medical instructions. As compliance remains a challenge in healthcare, and notably influenced by several other factors, our study is limited in this respect to clearly argue that as patients take responsibility in managing the health conditions, compliance levels will improve. Further research is needed to examine the post-encounter process, preferably employing a longitudinal experimental research design to study the entire process.

Our findings suggest the emergence of knowledge conflict in clinical encounters at the micro level resulting from the pre-encounter online information seeking. This affects actor experience in consultations, which is likely to moderate the encounter process and the expected service outcomes. Further research is needed to examine and measure this quantitatively to ascertain the effects.

Studies also show that women are more likely to seek health information online than are men. Furthermore, women are more focused of the searches and credibility of the information found than men (Cotten and Gupta, 2004). However, how this translates in consultations during clinical encounter is well established. Further research could test the relativities of gender effects using our model. 


\section{REFERENCES}

Alam, I., 2013. Customer Interaction in Service Innovation: Evidence from India. International Journal of Emerging Markets 8 (1), 41-64.

Anderson, J.C., Gerbing, D.W., 1988. Structural Equation Modeling in Practice: A Review and Recommended Two-Step Approach. Psychological bulletin 103 (3), 411-423.

Araz, O.M., Jehn, M., 2013. Improving Public Health Emergency Preparedness through Enhanced Decision-Making Environments: A Simulation and Survey Based Evaluation. Technological Forecasting and Social Change 80 (9), 1775-1781.

Arnett, D.B., German, S.D., Hunt, S.D., 2003. The Identity Salience Model of Relationship Marketing Success: The Case of Nonprofit Marketing. Journal of Marketing 67 (2), 89-105.

Auh, S., Bell, S.J., McLeod, C.S., Shih, E., 2007. Co-Production and Customer Loyalty in Financial Services. Journal of retailing 83 (3), 359-370.

Aveling, E.-L., Martin, G., 2013. Realising the Transformative Potential of Healthcare Partnerships: Insights from Divergent Literatures and Contrasting Cases in High-and Low-Income Country Contexts. Social Science \& Medicine 92 (September), 74-82.

Ayers, S.L., Kronenfeld, J.J., 2007. Chronic Illness and Health-Seeking Information on the Internet. Health: An Interdisciplinary Journal for the Social Study of Health, Illness and Medicine 11 (3), 327-347.

Bagozzi, R.P., Yi, Y., 1988. On the Evaluation of Structural Equation Models. Journal of the Academy of Marketing Science 16 (1), 74-94.

Bagozzi, R.P., Yi, Y., 2012. Specification, Evaluation, and Interpretation of Structural Equation Models. Journal of the Academy of Marketing Science 40 (1), 8-34.

Behkami, N.A., U. Daim, T., 2012. Research Forecasting for Health Information Technology (Hit), Using Technology Intelligence. Technological Forecasting and Social Change 79 (3), 498-508.

Berkman, N.D., Sheridan, S.L., Donahue, K.E., Halpern, D.J., Crotty, K., 2011. Low Health Literacy and Health Outcomes: An Updated Systematic Review. Annals of internal medicine 155 (2), 97-107.

Bitner, M.J., Booms, B.H., Tetreault, M.S., 1990. The Service Encounter: Diagnosing Favorable and Unfavorable Incidents. The Journal of Marketing 54 (1), 71-84.

Bitner, M.J., Faranda, W.T., Hubbert, A.R., Zeithaml, V.A., 1997. Customer Contributions and Roles in Service Delivery. International Journal of Service Industry Management 8 (3), 193-205.

Bove, L.L., Johnson, L.W., 2000. A Customer-Service Worker Relationship Model. International Journal of Service Industry Management 11 (5), 491-511.

Britten, N., Stevenson, F.A., Barry, C.A., Barber, N., Bradley, C.P., 2000. Misunderstandings in General Practice Prescribing Decisions: Qualitative Study. British Medical Journal 320), 1246-1250. 
Caridà, A., Colurcio, M., Melia, M., 2014. Rethinking and Improving the Health Care Service through Interactive Web Technologies, In: Baglieri, E., Karmarkar, U. (Eds), Managing Consumer Services. Springer, pp. 191-210.

Chandler, J.D., Vargo, S.L., 2011. Contextualization and Value-in-Context: How Context Frames Exchange. Marketing Theory 11 (1), 35-49.

Chen, S.-C., Quester, P.G., 2006. Modeling Store Loyalty: Perceived Value in Market Orientation Practice. Journal of Services Marketing 20 (3), 188-198.

Chou, D.C., Chou, A.Y., 2002. Healthcare Information Portal: A Web Technology for the Healthcare Community. Technology in Society 24 (3), 317-330.

Cotten, S.R., Gupta, S.S., 2004. Characteristics of Online and Offline Health Information Seekers and Factors That Discriminate between Them. Social Science \& Medicine 59 (9), 1795-1806.

Creswell, J.W., Plano Clark, V.L., 2011. Designing and Conducting Mixed Methods Research, 3 ed. Sage, Thousand Oaks, CA.

Daniel, K., Darby, D.N., 1997. A Dual Perspective of Customer Orientation: A Modification, Extension and Application of the Soco Scale. International Journal of Service Industry Management 8 (2), 131-147.

de Winter, A.F., Oldehinkel, A.J., Veenstra, R., Brunnekreef, J.A., Verhulst, F.C., Ormel, J., 2005. Evaluation of Non-Response Bias in Mental Health Determinants and Outcomes in a Large Sample of Pre-Adolescents. European journal of epidemiology 20 (2), 173-181.

Dellande, S., Gilly, M.C., Graham, J.J., 2004. Gaining Compliance and Losing Weight: The Role of the Service Provider in Health Care Services. Journal of Marketing 68 (July), 78-91.

Dubois, A., Gadde, L.-E., 2002. Systematic Combining: An Abductive Approach to Case Research. Journal of business research 55 (7), 553-560.

Echeverri, P., Skålén, P., 2011. Co-Creation and Co-Destruction: A Practice-Theory Based Study of Interactive Value Formation. Marketing Theory 11 (3), 351-373.

Elg, M., Engström, J., Witell, L., Poksinska, B., 2012. Co-Creation and Learning in HealthCare Service Development. Journal of Service Management 23 (3), 328-343.

Elwyn, G., Coulter, A., Laitner, S., Walker, E., Watson, P., Thomson, R., 2010. Implementing Shared Decision Making in the Nhs. British Medical Journal 341 (November), 971973.

Epp, A.M., Price, L.L., 2011. Designing Solutions around Customer Network Identity Goals. Journal of Marketing 75 (2), 36-54.

Eysenbach, G., Powell, J., Englesakis, M., Rizo, C., Stern, A., 2004. Health Related Virtual Communities and Electronic Support Groups: Systematic Review of the Effects of Online Peer to Peer Interactions. British Medical Journal 328 (7449), 1166.

Fiksdal, A.S., Kumbamu, A., Jadhav, A.S., Cocos, C., Nelsen, L.A., Pathak, J., McCormick, J.B., 2014. Evaluating the Process of Online Health Information Searching: A 
Qualitative Approach to Exploring Consumer Perspectives. Journal of medical Internet research 16 (10), e224.

Fox, S., Duggan, M., 2013. Health Online 2013. Health), 1-55.

Frow, P., Payne, A., 2011. A Stakeholder Perspective of the Value Proposition Concept. European Journal of Marketing 45 (1), 223-240.

Gallan, A.S., Jarvis, C.B., Brown, S.W., Bitner, M.J., 2013. Customer Positivity and Participation in Services: An Empirical Test in a Health Care Context. Journal of the Academy of Marketing Science 41 (3), 338-356.

GhanaHealthService. (2010). The Health Sector in Ghana: Facts and Figures. Retrieved 10 October, 2013, from http://www.ghanahealthservice.org/includes/upload/publications/Facts and Figures 2009

GhanaStatisticalService, 2014. Ghana Living Standards Round 6 - Main Report, August 2014 ed, Ghana

Gill, L., White, L., Cameron, I.D., 2011. Service Co-Creation in Community-Based Aged Healthcare. Managing Service Quality 21 (2), 152-177.

Godolphin, W., 2009. Shared Decision-Making. Healthcare Quarterly 12 (Special issue (August)), e186-e190.

Gummerus, J., Pihlström, M., 2011. Context and Mobile Services' Value-in-Use. Journal of Retailing and Consumer Services 18 (6), 521-533.

Gutierrez, N., Kindratt, T.B., Pagels, P., Foster, B., Gimpel, N.E., 2014. Health Literacy, Health Information Seeking Behaviors and Internet Use among Patients Attending a Private and Public Clinic in the Same Geographic Area. Journal of community health 39 (1), 83-89.

Hair, J.F., Tatham, R.L., Anderson, R.E., Black, W., 2006. Multivariate Data Analysis. Pearson Prentice Hall Upper Saddle River, NJ

Hajli, M.N., 2014. Developing Online Health Communities through Digital Media. International Journal of Information Management 34 (2), 311-314.

Hajli, M.N., Sims, J., Featherman, M., Love, P.E., 2015. Credibility of Information in Online Communities. Journal of Strategic Marketing 23 (3), 238-253.

Hardyman, W., Daunt, K.L., Kitchener, M., 2015. Value Co-Creation through Patient Engagement in Health Care: A Micro-Level Approach and Research Agenda. Public Management Review 17 (1), 90-107.

Harrison, R.L., Reilly, T.M., 2011. Mixed Methods Designs in Marketing Research. Qualitative Market Research: An International Journal 14 (1), 7-26.

Hartline, M.D., Maxham III, J.G., McKee, D.O., 2000. Corridors of Influence in the Dissemination of Customer-Oriented Strategy to Customer Contact Service Employees. Journal of Marketing 64 (2), 35-50. 
Hausman, A., 2004. Modeling the Patient-Physician Service Encounter: Improving Patient Outcomes. Journal of the Academy of Marketing Science 32 (4), 403-417.

Heidenreich, S., Handrich, M., 2015. Adoption of Technology-Based Services: The Role of Customers' Willingness to Co-Create. Journal of Service Management 26 (1), 44-71.

Helkkula, A., Kelleher, C., Pihlström, M., 2012. Characterizing Value as an Experience: Implications for Service Researchers and Managers. Journal of Service Research 15 (1), 59-75.

Hoyle, R.H., 1995. Structural Equation Modeling Approach: Basic Concepts and Fundamental Issues, In: Hoyle, R.H. (Ed), Structural Equation Modeling: Concepts, Issues, and Applications. Sage, Thousand Oaks, CA

Hsieh, A.-T., Yen, C.-H., Chin, K.-C., 2004. Participative Customers as Partial Employees and Service Provider Workload. International Journal of Service Industry Management 15 (2), 187-199.

Hu, L.-T., Bentler, P.M., 1999. Cutoff Criteria for Fit Indexes in Covariance Structure Analysis: Conventional Criteria Versus New Alternatives. Structural Equation Modeling: A Multidisciplinary Journal, 6 (1), 1-55.

Jaakkola, E., Halinen, A., 2006. Problem Solving within Professional Services: Evidence from the Medical Field. International Journal of Service Industry Management 17 (5), 409-429.

Jamal, A., Khan, S.A., AlHumud, A., Al-Duhyyim, A., Alrashed, M., Shabr, F.B., Alteraif, A., Almuziri, A., Househ, M., Qureshi, R., 2015. Association of Online Health Information-Seeking Behavior and Self-Care Activities among Type 2 Diabetic Patients in Saudi Arabia. Journal of medical Internet research 17 (8), e196.

Kaiser, H.F., 1970. A Second Generation Little Jiffy. Psychometrika 35 (4), 401-415.

Kaufmann, F., 1973. Hard and Soft Health Technology of the Future. Technological Forecasting and Social Change 5 (1), 67-74.

Kellogg, D.L., Youngdahl, W.E., Bowen, D.E., 1997. On the Relationship between Customer Participation and Satisfaction: Two Frameworks. International Journal of Service Industry Management 8 (3), 206-219.

Kim, K., 2000. On Interfirm Power, Channel Climate, and Solidarity in Industrial DistributorSupplier Dyads. Journal of the Academy of Marketing Science 28 (3), 388-405.

Kline, R.B., 2011. Principles and Practice of Structural Equation Modeling. Guilford Press, New York.

Kvale, S., Brinkmann, S., 2009. Interviews: Learning the Craft of Qualitative Research Interviewing. Sage, Thousand Oaks, CA.

Lai, J.-Y., Wang, J., 2015. Switching Attitudes of Taiwanese Middle-Aged and Elderly Patients toward Cloud Healthcare Services: An Exploratory Study. Technological Forecasting and Social Change $92(0), 155-167$.

Laing, A., Fischbacher, M., Hogg, G., Smith, A., 2002. Managing and Marketing Health Services. Thomson, Cornwall. 
Lemke, F., Clark, M., Wilson, H., 2011. Customer Experience Quality: An Exploration in Business and Consumer Contexts Using Repertory Grid Technique. Journal of the Academy of Marketing Science 39 (6), 846-869.

Lin, J.-S.C., Hsieh, C.-C., 2011. Modeling Service Friendship and Customer Compliance in High-Contact Service Relationships. Journal of Service Management 22 (5), 607-631.

Lunde, I.M., 1993. Patient's Perceptions - a Shift in Medical Perspective. Scandinavian Journal of Primary Health Care 11 (2), 98-104.

Lusch, R.F., Nambisan, S., 2015. Service Innovation: A Service-Dominant Logic Perspective. MIS quarterly 39 (1), 155-175.

Lusch, R.F., Vargo, S.L., 2014. Service-Dominant Logic: Premises, Perspectives, Possibilities. Cambridge University Press, Cambridge.

Mathieu, J.E., Taylor, S.R., 2006. Clarifying Conditions and Decision Points for Mediational Type Inferences in Organizational Behavior. Journal of Organizational Behavior 27 (8), 1031-1056.

McColl-Kennedy, J.R., Cheung, L., Ferrier, E., 2015. Co-Creating Service Experience Practices. Journal of Service Management 26 (2), 249-275.

McColl-Kennedy, J.R., Vargo, S.L., Dagger, T.S., Sweeney, J.C., van Kasteren, Y., 2012. Health Care Customer Value Cocreation Practice Styles. Journal of Service Research 15 (4), 370-389.

Nambisan, P., Nambisan, S., 2009. Models of Consumer Value Cocreation in Health Care. Health Care Management Review 34 (4), 344-354.

Oh, K.M., Zhou, Q.P., Kreps, G., Kim, W., 2013. The Influences of Immigration on Health Information Seeking Behaviors among Korean Americans and Native Koreans. Health Education \& Behavior 41 (2), 173-185.

Osei-Frimpong, K., Wilson, A., Owusu-Frimpong, N., 2015. Service Experiences and Dyadic Value Co-Creation in Healthcare Service Delivery: A Cit Approach. Journal of Service Theory and Practice 25 (4), 443-462.

Ostrom, A.L., Parasuraman, A., Bowen, D.E., Patricio, L., Voss, C.A., 2015. Service Research Priorities in a Rapidly Changing Context. Journal of Service Research 18 (2), 127-159.

Payne, A., Storbacka, K., Frow, P., Knox, S., 2009. Co-Creating Brands: Diagnosing and Designing the Relationship Experience. Journal of Business Research 62 (3), 379389.

Payne, A.F., Storbacka, K., Frow, P., 2008. Managing the Co-Creation of Value. Journal of the Academy of Marketing Science 36 (1), 83-96.

Peine, A., Moors, E.H.M., 2015. Valuing Health Technology - Habilitating and Prosthetic Strategies in Personal Health Systems. Technological Forecasting and Social Change $93(0), 68-81$.

Perreault, W.D., Leigh , L.E., 1989. Reliability of Nominal Data Based on Qualitative Judgments. Journal of marketing research 26 (2), 35-148. 
Peters, L.D., Lo bler, H., Brodie, R.J., Breidbach, C.F., Hollebeek, L.D., Smith, S.D., So rhammar, D., Varey, R.J., 2014. Theorizing About Resource Integration through Service-Dominant Logic. Marketing Theory 14 (3), 249-268.

Plé, L., Cáceres, R.C., 2010. Not Always Co-Creation: Introducing Interactional CoDestruction of Value in Service-Dominant Logic. Journal of Services Marketing 24 (6), 430-437.

Punjaisri, K., Wilson, A., 2011. Internal Branding Process: Key Mechanisms, Outcomes and Moderating Factors. European Journal of Marketing 45 (9/10), 1521-1537.

Saarijarvi, H., Kannan, P.K., Kuusela, H., 2013. Value Co-Creation: Theoretical Approaches and Practical Implications. European Business Review 25 (1), 6-19.

Saborowski, M., Kollak, I., 2015. “How Do You Care for Technology?” - Care Professionals' Experiences with Assistive Technology in Care of the Elderly. Technological Forecasting and Social Change 93 (0), 133-140.

Salanova, M., Agut, S., Peiró, J.M., 2005. Linking Organizational Resources and Work Engagement to Employee Performance and Customer Loyalty: The Mediation of Service Climate. Journal of Applied Psychology 90 (6), 1217-1227.

Sika Avortri, G., Beke, A., Abekah-Nkrumah, G., 2011. Predictors of Satisfaction with Child Birth Services in Public Hospitals in Ghana. International Journal of Health Care Quality Assurance 24 (3), 223-237.

Silver, M.P., 2015. Patient Perspectives on Online Health Information and Communication with Doctors: A Qualitative Study of Patients 50 Years Old and Over. Journal of medical Internet research 17 (1), e19.

Spohrer, J., Maglio, P.P., 2008. The Emergence of Service Science: Toward Systematic Service Innovations to Accelerate Co - Creation of Value. Production and operations management 17 (3), 238-246.

Tardy, R.W., Hale, C.L., 1998. Getting "Plugged In" : A Network Analysis of Health Information Seeking among "Stay - at - Home Moms" . Communications Monographs 65 (4), 336-357.

Taylor, K., 2009. Paternalism, Participation and Partnership - the Evolution of Patient Centeredness in the Consultation. Patient Education and Counseling 74 (2), 150-155.

Vargo, S.L., Lusch, R.F., 2008. Service-Dominant Logic: Continuing the Evolution. Journal of the Academy of Marketing Science 36 (1), 1-10.

Woo, J., Lee, M.J., Ku, Y., Chen, H., 2015. Modeling the Dynamics of Medical Information through Web Forums in Medical Industry. Technological Forecasting and Social Change 97 (0), 77-90.

WorldHealthOrganisation. (2015). Global Health Observatory Data Repository. $\begin{array}{llll}\text { Retrieved } 7 \text { March, 2016, from } & \end{array}$ http://apps.who.int/gho/data/node.main.78?lang=en

Yi, Y., Gong, T., 2013. Customer Value Co-Creation Behavior: Scale Development and Validation. Journal of business research 66 (9), 1279-1284. 
Zhao, J., Wang, T., Fan, X., 2015. Patient Value Co-Creation in Online Health Communities: Social Identity Effects on Customer Knowledge Contributions and Membership Continuance Intentions in Online Health Communities. Journal of Service Management 26 (1), 72-96. 


\section{CFA Results}

\section{Appendix 1}

\begin{tabular}{|c|c|c|c|}
\hline Item & Factor loading & $\mathbf{C R}$ & AVE \\
\hline Pre-Encounter Information Search & & 0.834 & 0.628 \\
\hline $\begin{array}{l}\text { I seek interest in searching for information relating to healthcare } \\
\text { using the internet }\end{array}$ & 0.885 & & \\
\hline $\begin{array}{l}\text { I ask others for information on related health issues using platforms } \\
\text { including online forums }\end{array}$ & 0.702 & & \\
\hline $\begin{array}{l}\text { Reading on health issues using online resources helps enhance my } \\
\text { knowledge to actively participate in consultations and could also } \\
\text { help manage my condition well }\end{array}$ & 0.780 & & \\
\hline Shared Decision-Making (Hausman, 2004) & & 0.936 & 0.745 \\
\hline $\begin{array}{l}\text { My doctor asks for suggestions from me regarding treatment } \\
\text { options }\end{array}$ & 0.872 & & \\
\hline $\begin{array}{l}\text { My doctor encourages suggestions about appropriate treatment of } \\
\text { my illness }\end{array}$ & 0.894 & & \\
\hline The doctor discussed the prescription with me & 0.896 & & \\
\hline Together, the doctor and I set goals and discuss treatment options & 0.886 & & \\
\hline I helped the doctor in planning my treatment & 0.761 & & \\
\hline Interaction (Chen and Quester, 2006) & & 0.877 & 0.704 \\
\hline The doctor initiated and fostered dialogue with me & 0.874 & & \\
\hline $\begin{array}{l}\text { The interaction was more conversational than questions and } \\
\text { answers }\end{array}$ & 0.798 & & \\
\hline $\begin{array}{l}\text { The doctor provided the enabling environment for me to actively } \\
\text { participate in the consultation }\end{array}$ & 0.844 & & \\
\hline The doctor established a good rapport with me & 0.837 & & \\
\hline Provider-Patient Orientation (Daniel and Darby, 1997) & & 0.856 & 0.599 \\
\hline The doctor is committed to understanding my needs & 0.853 & & \\
\hline The doctor considered me as his/her main priority & 0.813 & & \\
\hline The doctor allowed me to say everything I think is important & 0.713 & & \\
\hline The doctor makes recommendations that match my needs & 0.707 & & \\
\hline Improved Service Engagement (Salanova et al., 2005) & & 0.909 & 0.666 \\
\hline $\begin{array}{l}\text { A collaborative effort of the doctor and patient is more likely to } \\
\text { improve on the level of care }\end{array}$ & 0.825 & & \\
\hline The level of care delivered is excellent & 0.823 & & \\
\hline The doctor does more than usual in the engagement process & 0.833 & & \\
\hline The doctor is able to 'tune in' to me as unique & 0.833 & & \\
\hline The doctor is empathetic to my condition & 0.763 & & \\
\hline $\begin{array}{l}\text { Commitment to Compliance (Dellande et al., 2004; Hausman, } \\
\text { 2004) }\end{array}$ & & 0.861 & 0.675 \\
\hline $\begin{array}{l}\text { I return to the service provider based on the schedule he/she } \\
\text { suggests }\end{array}$ & 0.756 & & \\
\hline I am inclined to follow the instructions from the service provider & 0.775 & & \\
\hline $\begin{array}{l}\text { I accept and follow the advice from a doctor because I was } \\
\text { involved in the consultation process }\end{array}$ & 0.923 & & \\
\hline
\end{tabular}


Figure A.1: Model of micro level co-creation in a healthcare setting

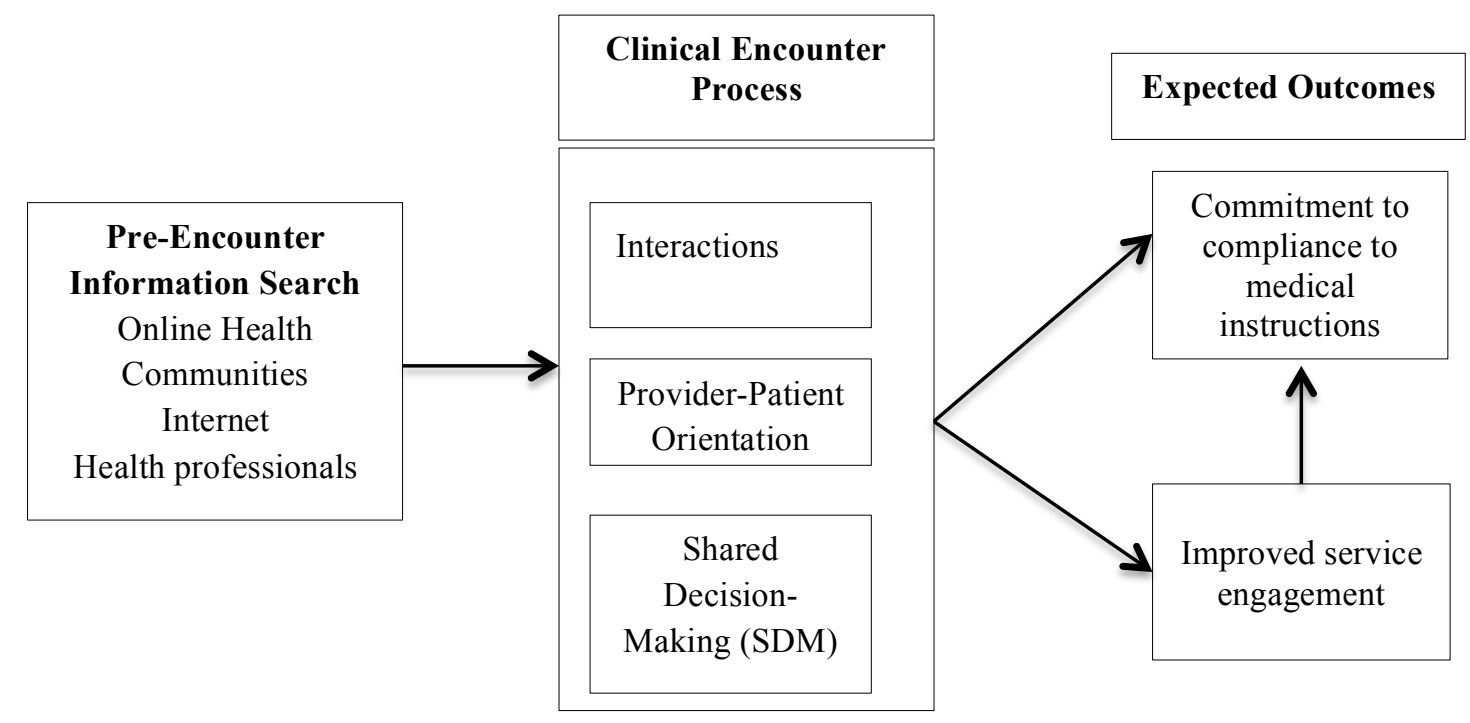


Figure A.2: Key constructs and path relationships

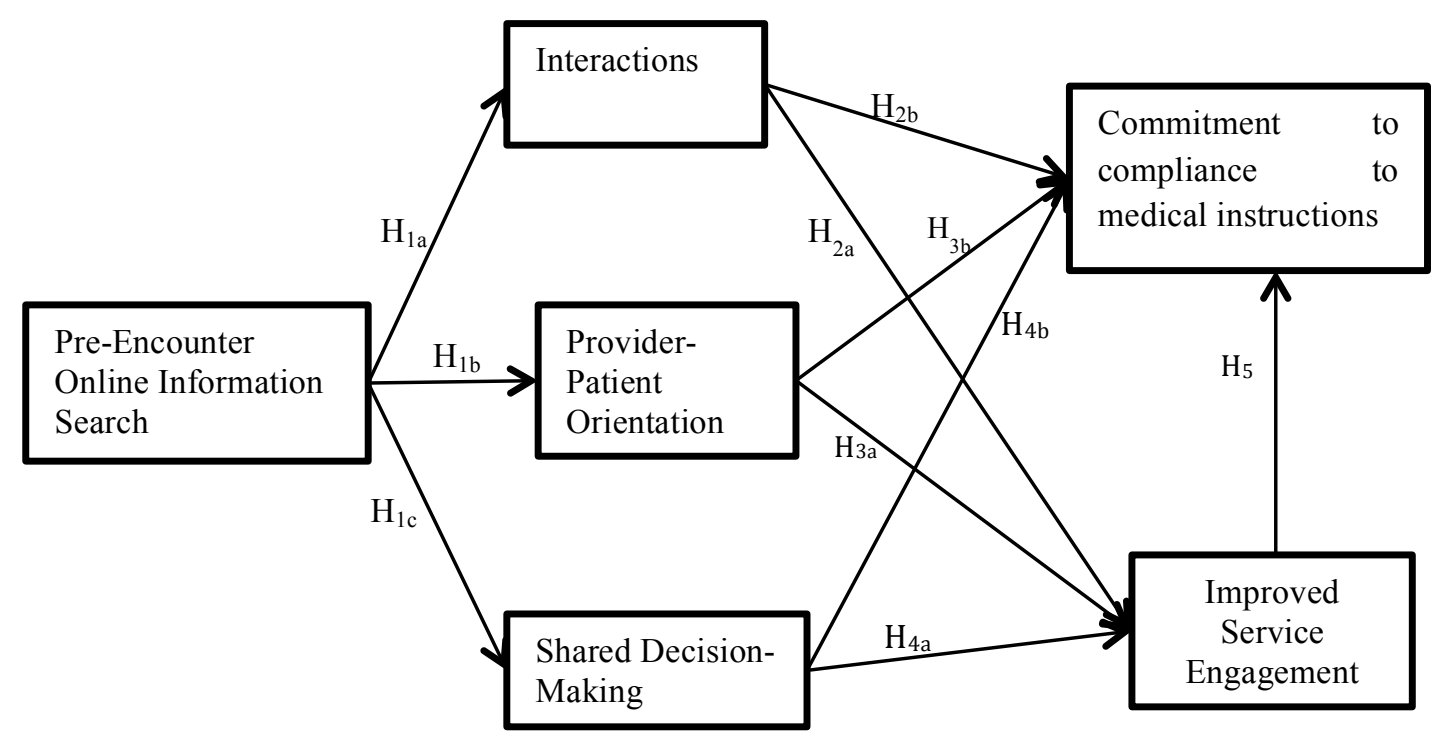


Table A.1: Characteristics of the respondents in the qualitative study

\begin{tabular}{llc}
\hline & Patient characteristics & Frequency (n) \\
\hline \multirow{2}{*}{ Gender } & Male & 8 \\
& Female & 12 \\
Age (in years) & $21-30$ & 4 \\
& $41-50$ & 6 \\
& $51-60$ & 8 \\
Educational & Senior High School & 2 \\
background & Higher National Diploma & 2 \\
& Undergraduate & 3 \\
& Bachelor's degree & 3 \\
& Post-Graduate degree & 10 \\
\hline Gender & Doctor characteristics & 2 \\
Professional & Male & Frequency (n) \\
rank & Female & 4 \\
& Junior Doctor & 3 \\
& Medical Officer & 4 \\
\hline
\end{tabular}


Table A.2: Themes and examples of quotes from interviews

\begin{tabular}{|c|c|}
\hline Themes & Examples quotes from interviews \\
\hline $\begin{array}{l}\text { Pre-encounter online } \\
\text { information search }\end{array}$ & 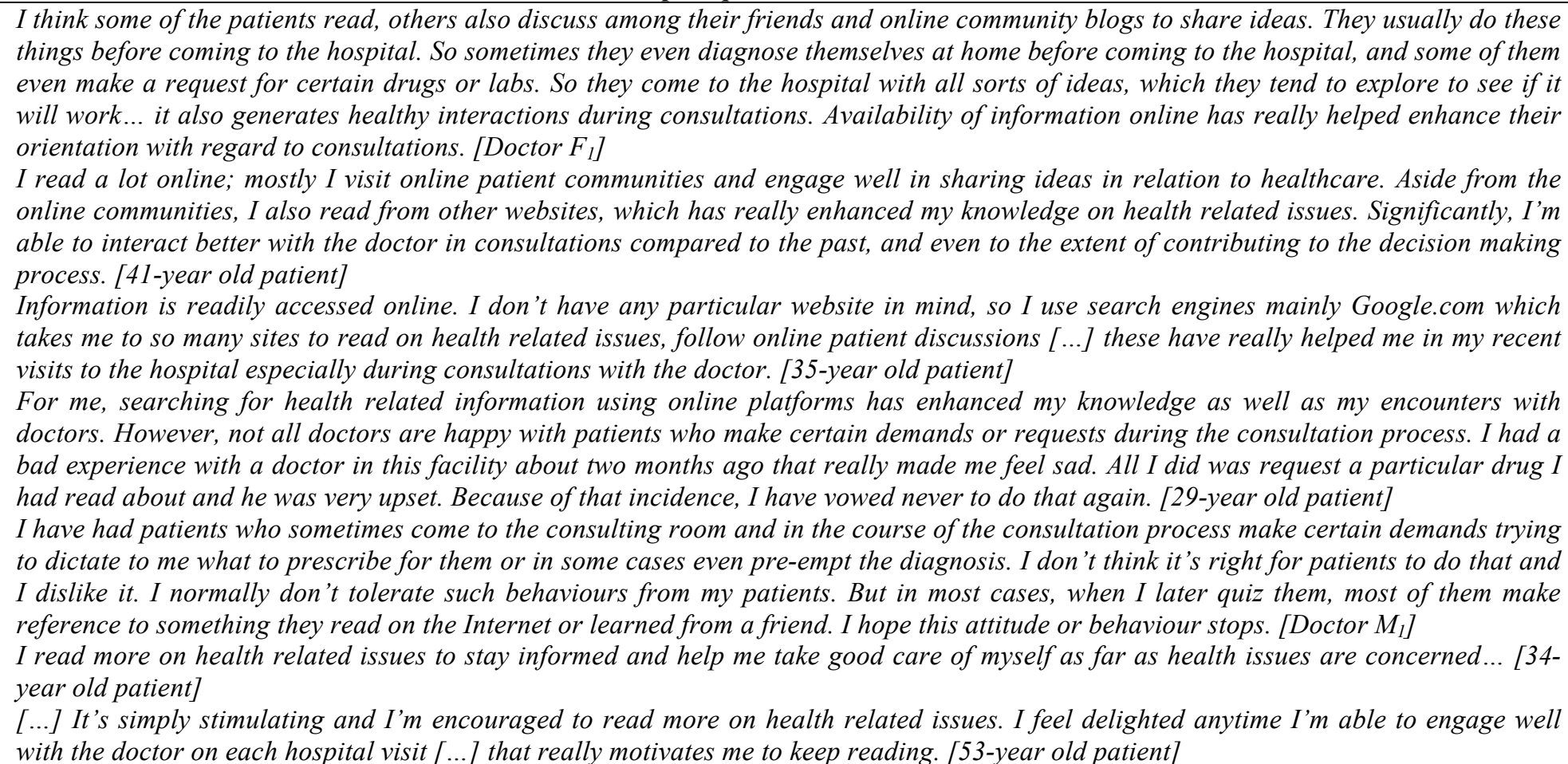 \\
\hline Interactions & $\begin{array}{l}\text { The consultation is mainly through interactions, it's a two-way communication, I need the patient to open up, share information with me } \\
\text { by reporting what is wrong with them, I come in and ask questions to probe further, they are also given the opportunity to ask questions or } \\
\text { say whatever is bothering them even to the extent that they are involved when a decision is taken. So during the consultation, I listen to } \\
\text { what they say, and I expect them also to listen to what I say. [Doctor } M_{3} \text { ] } \\
\text { I always try to be very active in the consultation, ensuring I interact well with the doctor. There are some doctors who will not offer that } \\
\text { opportunity, but even in such instances, I make sure I'm actively involved in the interactions to some extent. This is very important as it } \\
\text { gives me the chance to ask questions, seek for clarifications, and also gives me some sort of confidence in the system. [29-year-old patient] } \\
\text { The interaction phase of the consultation process is essential, however, the doctor has dominated most of my visits, and in some cases I'm }\end{array}$ \\
\hline
\end{tabular}




\begin{tabular}{|c|c|c|}
\hline \multicolumn{2}{|c|}{ Themes } & Examples quotes from interviews \\
\hline \multirow{5}{*}{$\begin{array}{l}\text { The } \\
\text { Encounter } \\
\text { Process }\end{array}$} & & $\begin{array}{l}\text { just rushed through without much interaction. This approach does not really help me as I expect the doctor to provide the enabling } \\
\text { environment to freely interact with him. [36-year-old patient] }\end{array}$ \\
\hline & Shared & $\begin{array}{l}\text { I prefer to be involved in the decision-making process. I want to share my opinions because at the end of the day, I'm the one expected to } \\
\text { follow the advice of the doctor. Hence, being involved gives me a sense of responsibility to ensure I comply. However, when this is denied, } \\
\text { it seems to me as if the doctor has just imposed something on me without my consent [...] [32-year old patient] }\end{array}$ \\
\hline & $\begin{array}{l}\text { Decision- } \\
\text { Making }\end{array}$ & $\begin{array}{l}\text { Sometimes, its good to involve the patient in the decision-making process, however, some patients are not forthcoming, others also take the } \\
\text { advantage to request for all manner of things [medications] that may not be useful in the condition, but it provides the avenue for me to } \\
\text { educate them as well. So I think its important to involve them in the decision-making process. [Doctor } F_{2} \text { ] }\end{array}$ \\
\hline & & $\begin{array}{l}\text { [...] I do not usually involve patients in the decision-making process because it is my duty to assess the patient's condition and provide } \\
\text { advice accordingly. Besides, patients trust whatever decision is made on their condition and therefore, I do not consider it necessary to } \\
\text { involve them. [Doctor } M_{1} \text { ] }\end{array}$ \\
\hline & $\begin{array}{l}\text { Provider- } \\
\text { Patient } \\
\text { Orientation }\end{array}$ & $\begin{array}{l}\text { I think understanding the doctor's behaviours in the consulting room is important as this helps me to engage with him [...] On the other } \\
\text { hand, I expect doctors to cooperate with me as a patient, understand my needs and engage well with me [45-year old patient] } \\
\text { Patients have needs and expectations and as a doctor, it is imperative to understand them and deliver a holistic service to satisfy their } \\
\text { needs, but ensuring the right thing is done. Likewise, patients' recent orientation of the consultation process has improved considerably, } \\
\left.\text { which seems to change the face of clinical encounters [Doctor } M_{3}\right]\end{array}$ \\
\hline \multirow{2}{*}{$\begin{array}{l}\text { The Post- } \\
\text { Encounter } \\
\text { Expected } \\
\text { Value } \\
\text { Outcomes }\end{array}$} & $\begin{array}{l}\text { Improved } \\
\text { Service } \\
\text { Engagement }\end{array}$ & $\begin{array}{l}\text { Changes in patients' attitude towards consultations are very important. Patients are now knowledgeable and active as a result of access to } \\
\text { information aided by the internet, which has improved the service engagement. When patients are actively involved in consultations, it } \\
\text { makes my work easier than with a patient who is shy and passive. [Doctor } M_{2} \text { ] } \\
\text { Online health information search has really helped me during consultations. I'm able to interact well with the doctor, ask questions, and } \\
\text { suggest options in some cases, which I couldn't do in the past. In all, I think the clinical engagement has improved. [28-year-old patient] }\end{array}$ \\
\hline & $\begin{array}{l}\text { Commitment } \\
\text { to } \\
\text { Compliance } \\
\text { to Medical } \\
\text { Instructions }\end{array}$ & $\begin{array}{l}\text { A positive approach to the engagement in the consulting room motivates me to be more committed to comply with the doctor's instruction. } \\
\text { [42-year old patient] } \\
\text { I expect improved commitment to compliance from my patients, which I think is mainly behavioural...my past experiences with some } \\
\text { patients make me believe that, however hard you try to engage and encourage patients, they go home and forget to take their } \\
\left.\text { medications... [Doctor } M_{4}\right]\end{array}$ \\
\hline
\end{tabular}


Table A.3: Qualitative key findings and propositions

\begin{tabular}{|c|c|c|c|}
\hline Theme/Variable & Definition & $\begin{array}{c}\text { Manifestations in consultations as reported in } \\
\text { findings }\end{array}$ & Propositions \\
\hline $\begin{array}{l}\text { Pre-Encounter } \\
\text { Information Search }\end{array}$ & $\begin{array}{l}\text { Activities patients engage in to purposively } \\
\text { acquire online healthcare information to enhance } \\
\text { their knowledge prior to the clinical encounters } \\
\text { that guide health-related decision making (Oh et } \\
\text { al., 2013; Tardy and Hale, 1998) }\end{array}$ & $\begin{array}{l}\text { Patients are confident in submissions } \\
\text { Active involvement in deliberations } \\
\text { Doctors false impressions about patients }\end{array}$ & $\begin{array}{l}\text { Proposition 1: } \frac{\text { Pre-encounter }}{\text { information search is more likely to }} \\
\text { enlighten patients and influence the } \\
\text { encounter process by increasing the } \\
\text { level of interaction and patients' } \\
\text { preparedness to engage in a shared } \\
\text { decision-making approach during } \\
\text { consultations. }\end{array}$ \\
\hline Interactions & $\begin{array}{l}\text { Interaction is referred to as a reciprocal action } \\
\text { between two or more actors that require "mutual } \\
\text { trust and collaborative relationships" (Alam, } \\
2013 \text {, p. 58) }\end{array}$ & $\begin{array}{l}\text { Two-way communication between doctor and } \\
\text { patient } \\
\text { Patients do not just present their symptoms but go } \\
\text { beyond to discuss issues without reticence } \\
\text { Patients }\end{array}$ & $\begin{array}{l}\text { Proposition 2: Enhanced interactions are } \\
\text { likely to improve on level of service } \\
\text { engagement and increase patient } \\
\text { commitment to compliance }\end{array}$ \\
\hline $\begin{array}{l}\text { Patient-Provider } \\
\text { Orientation }\end{array}$ & $\begin{array}{l}\text { Responsive customer orientation refers to a } \\
\text { provider's capability to respond effectively to } \\
\text { satisfy customers' expressed needs (Bove and } \\
\text { Johnson, 2000) }\end{array}$ & $\begin{array}{l}\text { A need to understand each actor in the encounter } \\
\text { Doctors orient to be abreast of patient changing } \\
\text { behaviours }\end{array}$ & $\begin{array}{l}\text { Proposition 3: Improved patient-provider } \\
\text { orientation is likely to impact positively on } \\
\text { expected service outcomes }\end{array}$ \\
\hline $\begin{array}{l}\text { Shared Decision- } \\
\text { Making }\end{array}$ & $\begin{array}{l}\text { An approach where clinicians and patients share } \\
\text { the best available evidence when faced with the } \\
\text { task of making decisions, and where patients are } \\
\text { supported to consider options, to achieve } \\
\text { informed preferences (Elwyn et al., 2010) }\end{array}$ & $\begin{array}{l}\text { Share detailed information and allow patients to } \\
\text { deliberate and intimate their preferences and } \\
\text { opinions during the decision-making process } \\
\text { Doctors allow patients to suggest treatment } \\
\text { options as a result of their enhanced knowledge } \\
\text { Patients take full responsibility of managing their } \\
\text { condition as a result of being part of the decision } \\
\text { making process }\end{array}$ & $\begin{array}{l}\text { Proposition 4: Patients involvement in } \\
\text { shared decision making motivates them to } \\
\text { take full responsibility of their condition } \\
\text { which is likely to help improve on the } \\
\text { expected outcomes }\end{array}$ \\
\hline Expected Outcomes & $\begin{array}{l}\text { Anticipated outcomes that could ensue resulting } \\
\text { from the pre-encounter activities and encounter } \\
\text { process }\end{array}$ & $\begin{array}{l}\text { The possibility of patient getting well leading to } \\
\text { value created for both actors } \\
\text { Improved service engagement } \\
\text { Increased patient commitment to compliance }\end{array}$ & $\begin{array}{l}\text { Proposition 5: value is co-created taking } \\
\text { into consideration the pre-encounter and } \\
\text { encounter process in the healthcare } \\
\text { delivery }\end{array}$ \\
\hline
\end{tabular}


Table A.4: Characteristics of the respondents in the quantitative study

\begin{tabular}{llcc}
\hline & Patient characteristics & Frequency (n) & Percentage (\%) \\
\hline \multirow{3}{*}{ Gender } & Male & 120 & 33 \\
& Female & 240 & 67 \\
& $21-30$ & 141 & 39 \\
Age (in years) & $31-40$ & 107 & 30 \\
& $41-50$ & 41 & 11 \\
& $51-60$ & 71 & 20 \\
& & & 39 \\
Educational & Senior High School & 142 & 7 \\
background & Diploma & 24 & 13 \\
& Higher National Diploma & 45 & 8 \\
& Undergraduate & 30 & 11 \\
& Bachelor's degree & 40 & 4 \\
& Post-Graduate degree & 15 & 18 \\
\hline
\end{tabular}

Note: *Respondents with basic education below Senior High School 
Table A.5: Validity and composite reliability measures

\begin{tabular}{|c|c|c|c|c|c|c|c|c|c|c|}
\hline & Mean & SD & $\mathbf{C R}$ & AVE & PPO & SDM & PEIS & INT & CCM & ISE \\
\hline $\begin{array}{l}\text { Provider-Patient } \\
\text { Orientation (PPO) }\end{array}$ & 3.92 & 0.77 & 0.856 & 0.599 & 0.774 & & & & & \\
\hline $\begin{array}{l}\text { Shared Decision-Making } \\
(\mathrm{SDM})\end{array}$ & 3.36 & 0.68 & 0.936 & 0.745 & 0.347 & 0.863 & & & & \\
\hline $\begin{array}{l}\text { Pre-Encounter Online } \\
\text { Information Search } \\
\text { (PEIS) }\end{array}$ & 3.62 & 1.12 & 0.834 & 0.628 & 0.210 & 0.390 & 0.793 & & & \\
\hline Interaction (INT) & 3.39 & 1.01 & 0.877 & 0.704 & 0.236 & 0.228 & 0.233 & 0.839 & & \\
\hline $\begin{array}{l}\text { Commitment to } \\
\text { Compliance (CCM) }\end{array}$ & 4.09 & 0.67 & 0.861 & 0.675 & 0.464 & 0.240 & 0.258 & 0.166 & 0.821 & \\
\hline $\begin{array}{l}\text { Improved Service } \\
\text { Engagement (ISE) }\end{array}$ & 3.98 & 0.77 & 0.909 & 0.666 & 0.444 & 0.263 & 0.144 & 0.450 & 0.220 & 0.816 \\
\hline
\end{tabular}

Note: SD - Standard Deviation 
Table A.6: Structural parameter estimates (standardized coefficients)

\begin{tabular}{|c|c|c|c|c|c|c|c|c|c|}
\hline \multirow[t]{2}{*}{ Path } & \multicolumn{3}{|c|}{ Focal Model } & \multicolumn{3}{|c|}{ Alternative model 1} & \multicolumn{3}{|c|}{ Alternative model 2} \\
\hline & $\beta$ & t - value & $\mathbf{R}^{2}$ & $\beta$ & t - value & $\mathbf{R}^{2}$ & $\beta$ & t - value & $\mathbf{R}^{2}$ \\
\hline Pre-encounter online information search $\rightarrow$ Nature of Interactions $\left(\mathbf{H}_{1 \mathbf{a}}\right)$ & $.421^{* *}$ & 2.353 & .177 & $.420^{* *}$ & 2.340 & .176 & $.423^{* *}$ & 1.984 & .179 \\
\hline Pre-encounter online information search $\rightarrow$ Provider-Patient Orientation $\left(\mathbf{H}_{1 \mathbf{b}}\right)$ & $.337^{* *}$ & 2.217 & .114 & $.340^{* *}$ & 2.262 & .116 & $.329^{* *}$ & 2.082 & .108 \\
\hline Pre-encounter online information search $\rightarrow$ Shared Decision-Making $\left(\mathbf{H}_{\mathbf{1 c}}\right)$ & $.312^{* * *}$ & 5.254 & .097 & $.312^{* * *}$ & 5.259 & .097 & $.313^{* * *}$ & 5.276 & .098 \\
\hline Nature of Interactions $\rightarrow$ Improved Service Engagement $\left(\mathbf{H}_{\mathbf{2} \mathbf{a}}\right)$ & $.312^{* * *}$ & 3.955 & .380 & $.312^{* * *}$ & 3.955 & .378 & $.310^{* * *}$ & 3.953 & .362 \\
\hline Nature of Interactions $\rightarrow$ Commitment to Compliance $\left(\mathbf{H}_{2 b}\right)$ & $.164^{* *}$ & 2.882 & .361 & $.195^{* * *}$ & 3.211 & .360 & $.131^{* *}$ & 2.016 & .330 \\
\hline Provider-Patient Orientation $\rightarrow$ Improved Service Engagement $\left(\mathbf{H}_{\mathbf{3 a}}\right)$ & $.337^{* * *}$ & 5.208 & & $.459^{* * *}$ & 6.512 & & $.335^{* * *}$ & 5.120 & \\
\hline Provider-Patient Orientation $\rightarrow$ Commitment to Compliance $\left(\mathbf{H}_{\mathbf{3 b}}\right)$ & $.074^{\mathrm{ns}}$ & 0.245 & & $.069^{\mathrm{ns}}$ & 1.175 & & -- & -- & \\
\hline Shared Decision-Making $\rightarrow$ Improved Service Engagement $\left(\mathbf{H}_{\mathbf{4}}\right)$ & $.615^{* * *}$ & 4.740 & & $.612^{* * *}$ & 4.720 & & $.610^{* * *}$ & 4.711 & \\
\hline Shared Decision-Making $\rightarrow$ Commitment to compliance $\left(\mathbf{H}_{\mathbf{4 b}}\right)$ & $.322^{* *}$ & 2.342 & & $.321^{* *}$ & 2.342 & & $.208^{* * *}$ & 3.157 & \\
\hline Improved service engagement $\rightarrow$ Commitment to Compliance $\left(\mathbf{H}_{5}\right)$ & $.385^{* * *}$ & 5.891 & & -- & -- & & -- & -- & \\
\hline Goodness-of-fit statistics: & $\begin{array}{l}\chi_{(232)}^{2}= \\
\text { GFI = } \\
\text { AGFI = } \\
\text { CFI }= \\
\text { TLI = } \\
\text { RMSEA } \\
\text { PCLOS } \\
\text { AIC }=\end{array}$ & $\rho=.165$ & & $\begin{array}{l}\chi_{(233)}^{2}= \\
\text { GFI }= \\
\text { AGFI = } \\
\text { CFI }= \\
\text { TLI = } \\
\text { RMSE } \\
\text { PCLOS } \\
\text { AIC }\end{array}$ & $\begin{array}{l}41.218, \rho= \\
11 \\
385 \\
57 \\
49 \\
=.050 \\
=.500 \\
575.218\end{array}$ & 083 & $\begin{array}{l}\chi_{(234)}^{2}= \\
\text { GFI = } \\
\text { AGFI = } \\
\text { CFI }= \\
\text { TLI = } \\
\text { RMSE } 1 \\
\text { PCLOS } \\
\text { AIC }\end{array}$ & $\begin{array}{l}91.992, \rho= \\
02 \\
874 \\
947 \\
938 \\
=.055 \\
=.095 \\
623.992\end{array}$ & 063 \\
\hline
\end{tabular}

$\rho<0.001 ;{ }^{* *} \rho<0.05 ;{ }^{n s}$ Not significant 